\title{
La noción republicana de ciudadanía y la diversidad cultural *
}

\author{
JuAN CARlos Velasco \\ Instituto de Filosofía del CSIC
}

RESUMEN. En este artículo se aborda la cuestión de la diversidad cultural contemplada desde la concepción republicana de la ciudadanía en tres pasos: en el primero, se presenta el sentido polisémico de la noción de ciudadanía y la acelerada evolución que ha experimentado en los últimos tiempos; en un segundo paso, se ofrecen los rasgos generales que caracterizan el enfoque neorrepublicano; $y$, finalmente, se da cuenta de las virtualidades que ofrece una relectura de los tópicos republicanos para integrar la pluralidad de culturas y formas de vida que conviven en las complejas sociedades contemporáneas a raíz de los procesos migratorios.

Palabras clave: ciudadanía, pluralismo cultural, republicanismo, democracia, liberalismo, identidad, políticas migratorias.

Al escoger el título de este artículo se está dando ya por firmemente asentada la relevancia cívico-política de los problemas suscitados por la diversidad cultural. Esta presuposición se apoya - al menos implícitamente - en el reconocimiento de la pluralidad de culturas en las sociedades contemporáneas no sólo como constatación empírica de un rasgo estructural de las mismas, sino también como un hecho ineludible para cualquier reflexión significativa sobre la política. Éste es también el
ABSTRACT. In this article the question of cultural diversity as it appears in the perspective of a republican conception of citizenship is discussed within three steps: in a first step, the ambiguous sense of the notion «citizenship» and its recently accelerated evolution will be presented; in a second step, the general features of the neo-republican approach will be outlined; and finally, the chances offered by a relecture of the republican topics with regard to an integration of the plurality of cultures and ways of life, which coexist within the complex contemporary societies and which base on migration processes, will be brought to mind.

Keywords: citizenship, cultural pluralism, republicanism, democracy, liberalism, identity, migration policies.

punto de partida del liberalismo preconizado por el «segundo Rawls»: el reconocimiento del hecho del pluralismo, esto es, de la existencia de discrepancias irreductibles entre los ciudadanos de una misma sociedad sobre asuntos cruciales, tales como las concepciones del mundo o los códigos culturales (cfr. Rawls, 1996). No obstante, el dato desnudo no resulta en sí mismo problemático: culturas en contacto e incluso compartiendo un mismo territorio se han dado siempre a lo largo de la

\footnotetext{
* El presente trabajo se realizó durante el verano de 2005 en una estancia de investigación en la Technische Universität de Berlín, financiada por la Deutsche Forschungsgemeinschaft (DFG). Mi agradecimiento a Mirian Galante por la revisión del manuscrito original y por sus atinados comentarios.
} 
historia. Aunque la circunstancia de que en un mismo espacio social convivan individuos portadores de diversos valores y concepciones, de que existan sociedades heterogéneas cultural, nacional y étnicamente, es casi tan antigua como la propia humanidad, y a pesar de que esa diversidad se haya relevado con frecuencia como fuente de riqueza y progreso, a nadie se le esconde que este hecho también puede darse conformando un escenario de tensiones y riesgos: «riesgo de que cada una de las comunidades culturales cancele, desde su interior, la libertad de sus propios individuos; riesgo también de que las comunidades de mayor fuerza y tradición cierren la posibilidad de desarrollo de las más débiles; finalmente, de que la cultura nacional, que es el cemento que une a la sociedad más amplia, se debilite y llegue a la desintegración total» (Salmerón, 1996, p. 70). Es esta percepción negativa la que ha pasado ahora a ocupar la primera línea, haciendo de la diversidad cultural objeto de reiterada preocupación.

A la hora de tratar esta forma de diversidad, mucha es la algarabía creada, a veces de manera interesada, pues en un mismo debate se entrecruzan con harta frecuencia la inmigración, la convivencia intercultural, el choque de civilizaciones y hasta la posibilidad de la desmembración de las sociedades, por aludir tan sólo a algunos de los tópicos más habituales. En todo caso, los riesgos y tensiones señalados son tan relevantes que no pueden ser escamoteados en un planteamiento político global. No es entonces casualidad que la filosofía política de las últimas décadas haya convertido la diversidad cultural en uno de los temas centrales de su reflexión '. Y no sólo desde la filosofía política en general, sino desde las diferentes corrientes de pensamiento político se ha tratado de dar respuesta a esta cuestión. Las aproximaciones más conocidas son las efectuadas desde el pensamiento demócrata-liberal, que no en vano oficia en la actualidad como pensamiento dominante (aunque no único, por más que algunos deseen considerarlo así). Otros planteamientos políticos, que pretenden presentarse como alternativas, o al menos como correcciones a la ortodoxia dominante, también tienen algo que decir sobre el tema. Éste sería el caso del republicanismo, cuyas propuestas son precisamente las que se quieren analizar en este trabajo.

Al hablar de republicanismo es inevitable la referencia a aquella corriente de pensamiento político surgida en algunas municipalidades italianas del renacimiento que confirió nuevo sentido a las tradiciones ciudadanas griegas y romanas, animó gran parte de los debates políticos de la Inglaterra de los siglos XVII y XVIII, influyó sobre los padres fundadores de la independencia estadounidense $y$, tras casi dos siglos de discreto silencio, ha llegado hasta nuestros días como soporte de los clásicos ideales del vivere libero. Tras protagonizar un inesperado renacer, las contribuciones de numerosos filósofos políticos y iusfilósofos neorrepublicanos contemporáneos han tenido la virtud de volver a plantear la cuestión de la libertad republicana -y el correspondiente rechazo de cualquier forma de servidumbreno sólo como un problema histórico, sino también como un asunto filosófico de relevancia no coyuntural. No obstante, es preciso advertir que el nuevo republicanismo, al menos el que aquí se reivindica, representa una reconstrucción selectiva de esa tradición (una tradición que, por otro lado, nunca generó una ortodoxia escolástica, ni constituyó un conjunto coherente y sistemático de postulados políticos), de la que conscientemente se resaltan ciertos motivos y se desechan otros. En todo caso, y al no tratarse de una concepción cerrada, se parte del convencimiento de que «para los republicanos contemporáneos, la tarea no se reduce a escarbar», pues «la historia no nos provee de concepciones de la vida política que puedan trasladarse mecánica- 
mente a los problemas actuales» (Sunstein, 2004, p. 137). Hacen por ello una lectura parcial de la historia de la propia tradición republicana, una lectura que puede acaso ser tildada de reflexión desmemoriada y de que toma los conceptos en abstracto, sin atender a su contexto de formación ni a su encarnación histórica, pero no de rememoración meramente historicista. Tampoco ha de extrañar que desde lecturas plurales de una rica tradición, los diversos teóricos políticos contemporáneos conocidos como republicanos - Quentin Skinner, Philip Pettit, Cass Sunstein, Maurizio Viroli, Jürgen Habermas y un largo etcétera- presenten perfiles bien diferenciados y no siempre conciliables (cfr. Ferrara, 2004). Si bien es cierto que la actual revitalización del republicanismo adolece, pese a su innegable aire academicista, de una notable imprecisión conceptual, sus diversos representantes poseen un cierto aire de familia que los hace reconocibles en la medida en que tienden a rescatar de esa tradición política su compromiso con ciertos tópicos, entre los que descuellan los siguientes: la igualdad política, la deliberación pública, el combate de la corrupción y, de forma eminente, la reivindicación de la ciudadanía.

En este artículo se abordará la cuestión de la diversidad cultural contemplada desde la concepción republicana de la ciudadanía en tres pasos consecutivos: en el primero, se presentará el sentido polisémico de la noción de ciudadanía y la acelerada evolución que ha experimentado en los últimos tiempos (1); en un segundo paso, se ofrecen los rasgos generales que caracterizan en enfoque neorrepublicano (2); y, finalmente, se dará cuenta de las virtualidades que ofrece una relectura de los tópicos republicanos para integrar la pluralidad de culturas y formas de vida que conviven en las complejas sociedades contemporáneas sobre todo a raíz de la intensificación de los flujos migratorios (3).

\section{La noción de ciudadanía en el debate contemporáneo}

La recuperación de la noción de ciudadanía experimentada en las últimas décadas ayuda a explicar en una gran medida el renovado interés por la tradición republicana. Cuando hoy se invoca esta tradición política como portadora de un robusto modelo normativo de ciudadanía resulta evidente que con ello se está pretendiendo conceder una base teórica respetable a los repetidos llamamientos dirigidos a alentar el espíritu participativo y solidario en las sociedades contemporáneas. La vinculación entre ciudadanía, por un lado, y republicanismo y participación cívica, por otro, no es, sin embargo, la única que cabe establecer. Ciudadanía es una categoría multidimensional que simultáneamente puede fungir como concepto legal, ideal político igualitario y referencia normativa para las lealtades colectivas. Implica en principio una relación de pertenencia con una determinada politeia (o comunidad política), una relación asegurada en términos jurídicos, pero también denota una forma de participación activa en los asuntos públicos ${ }^{2}$. Por un lado, supone una condición de status y, por otro, define una práctica política.

Un dato empírico para mostrar el dinamismo y - todo hay que decirlo - también el cierto grado de confusión con el que se ha presentado la reflexión sobre la ciudadanía: sólo en el intervalo comprendido entre 1989 y 1995 se presentaron en el ámbito anglosajón al menos seis elaboradas propuestas para replantear el concepto: ciudadanía diferenciada (Young, 1989), ciudadanía postnacional (Soysal, 1994), ciudadanía neorrepublicana (van Gunsteren, 1994), ciudadanía cultural (Turner, 1994), ciudadanía multicultural (Kymlicka, 1995), ciudadanía transnacional (Bauböck, 1995). Desde entonces este inventario no ha dejado de aumentar: «La lista de nuevos adjetivos puede alargarse y 
no hay ninguna duda de que así será. Todos estos nuevos lemas apuntan hacia la propagación de la idea clásica de ciudadanía social defendida por Thomas Marshall y la exploración de nuevos significados de la participación en los procesos de toma de decisiones públicas» (Baumann, 2001, p. 172). Precisamente por ello el grado de dispersión semántica es algo menor que lo que en una primera impresión pudiera parecer, pues la remisión a Marshall resulta prácticamente obligada y de alguna manera ayuda a unificar los términos de la discusión ${ }^{3}$. No obstante, esta común referencia no nos debe hacer olvidar que, como se acaba de apuntar, en el debate sobre la ciudadanía confluyen y se enfrentan al menos dos lenguajes políticos diferentes: bien como «condición legal» (la plena pertenencia a una comunidad política particular) o bien como «actividad deseable» (vinculada a la participación en el destino de la comunidad política). La primera lectura como visión básica del asunto es la que el liberalismo ha propiciado tradicionalmente. Derechos y ciudadanía constituyen dos ingredientes básicos de la concepción liberal de la política: la ciudadanía representaría en este caso el estatuto jurídico que sirve de soporte para el conjunto de derechos que pueda disfrutar un individuo. Por su parte, el tratamiento de la segunda acepción deviene a menudo en un lenguaje de las virtudes públicas o, lo que es lo mismo, en un discurso republicano sobre las virtudes del buen ciudadano, definidas éstas como un conjunto de predisposiciones hacia el bien común necesarias para otorgar estabilidad y vigor a las instituciones democráticas. Desde una perspectiva en parte confluyente con la anterior, como es la expresada por autores como Hannah Arendt o Maurizio Viroli, la ciudadanía se identificaría también con el autocontrol democrático, esto es, con la capacidad de autogobierno de los sujetos mediante la participación activa en la esfera pública.
Sea de una manera o de otra, el interés que los filósofos políticos contemporáneos reservan a las cuestiones relativas a la ciudadanía viene a cubrir un importante vacío dejado por la teoría rawlsiana (cfr. Thiebaut, 1998). En el nivel teórico, la atención prestada a este tema desde hace un par de décadas puede entenderse como una derivación de la polémica que mantuvieron durante años liberales y comunitaristas: «se trata de una evolución natural del discurso político, ya que el concepto de ciudadanía parece integrar las exigencias de justicia y de pertenencia comunitaria, que son respectivamente los conceptos centrales de la filosofía política de los años setenta y ochenta. El concepto de ciudadanía está íntimamente ligado, por un lado, a la idea de los derechos individuales $y$, por el otro, a la noción de vínculo con una comunidad particular» (Kymlicka y Norman, 1997, p. 5). Sea cierto o no, eso es lo de menos, los comunitaristas habrían tenido éxito al difundir la sospecha de que tras las pretensiones de una ética universalista como la rawlsiana se escondería la quiebra de las lealtades particulares en aras de un vaporoso cosmopolitismo ${ }^{4}$. Frente a la ingenua convicción liberal de que una concepción compartida de la justicia aporta los necesarios vínculos de cohesión social, desde otras perspectivas no completamente opuestas se niega que esto sea una consecuencia necesaria y consideran aún menos evidente que el participar de dicha concepción genere «una identidad ciudadana compartida que supere las identidades rivales basadas en la etnicidad. Parece claro, pues, que éste es un punto donde necesitamos una teoría de la ciudadanía y no solamente una teoría de la democracia o de la justicia» (Kymlicka y Norman, 1997, pp. 32-33).

El retorno de la figura del ciudadano se encuentra conectado, no obstante, con la revitalización que de manera casi simultánea ha experimentado el discurso sobre la sociedad civil y su conversión en objeto 
de intenso debate académico e ideológico. Más allá de que la sociedad civil se conciba, al modo de Tocqueville, como la serie de «estamentos intermedios» entre el individuo y el Estado o se presente, al modo de Arendt o Habermas, como una estancia regulativa que cribe las iniciativas políticas desde el cedazo de los intereses generalizables, ya el mismo hecho de postularla incluye en sí una demanda de una mayor implicación personal de los actores en la esfera pública, esto es, que los ciudadanos asuman su papel de sujetos activos de una comunidad política. Aunque no se puede negar que en el renacer de dicho discurso hubo, sin duda, un componente de moda intelectual provocada en gran parte por los procesos de democratización en el Sur de Europa en los años setenta, en América Latina en los ochenta y en Europa del Este a partir de la caída del muro de Berlín, también es cierto que conecta con una potente tradición de pensamiento político (cfr. Cohen y Arato, 2000).

El sentido del término ciudadanía ha ido evolucionando a lo largo del tiempo a un ritmo parejo al que iba transmutándose la naturaleza del vínculo político. En el mundo actual, el Estado, concebido como entidad política soberana de base territorial y forma organizativa básica, ha sido reiteradamente cuestionado por procesos de integración supranacional y transnacional, por un lado, y por procesos de descentralización y fragmentación, por otro. De modo similar, la nación en tanto que tipo particular de comunidad política y en tanto que modo singular de lealtad también ha sido puesta en cuestión por la irrupción de formas de identidad nuevas y más complejas, particularmente formas postnacionales, multinacionales y poliétnicas. La transformación del Estado-nación y la emergencia de nuevos modos de lealtad representan desafíos ineludibles que han de ser encarados desde la teoría política con el objeto de pensar nuevas fórmulas de vivir en común. La enorme difusión de la noción de ciudadanía en las ciencias sociales y en la agenda política va unida en gran medida a un intento de extender su campo de aplicación. El concepto ha demostrado poseer un carácter enormemente dinámico, en continua adaptación a situaciones y contextos diversos. La historia jurídico-política de la humanidad es, en gran medida, la historia de la lucha por la ciudadanía, de su reconocimiento y extensión a todos los seres humanos. En esta línea se han dado pasos importantes en los últimos siglos, sobre todo a partir de las revoluciones del XVHI, pero la universalización de la condición de ciudadanos -y con ella de la condición a ser titular del «derecho a tener derecho»- aún dista mucho de ser completa y esta carencia origina no pocas veces situaciones de injusticia. A este respecto, no puede ocultarse que el status de ciudadanía de determinados Estados (principalmente, de las ricas democracias occidentales, aunque no sólo) se han convertido en un bien cada día más apreciado, en un título anhelado por los habitantes de los países desfavorecidos que aguardan junto a sus fronteras la oportunidad de acceder y residir en esos territorios de presunta promisión. La historia de la ciudadanía se revela entonces también como la historia de la dialéctica de la inclusión y la exclusión por medio de la cual se va delimitando el demos constitutivo de una determinada comunidad política. La construcción social del ciudadano y del extranjero son respectivamente la cara y la cruz de un mismo proceso. Esta ambigüedad constitutiva del término no puede ser pasada por alto. De ahí que hablar, por ejemplo, de la ciudadanía como una garantía frente al atropello y la arbitrariedad suene para muchos a amargo sarcasmo, precisamente para aquellos que al verse desprovistos de sus beneficios comprueban que se ha convertido en un factor de exclusión social.

El trato que los Estados soberanos territoriales dispensan a los extranjeros 
que se afincan en el interior de sus fronteras es la piedra con la que con mayor frecuencia se tropieza a la hora de dar respuesta cabal a la reivindicación de una ciudadanía igual para todos los individuos, sea cual sea su sexo, religión, cultura, ideología o procedencia. Con la ciudadanía va unida el reconocimiento de derechos, cuya cantidad y calidad ha ido ampliándose paulatinamente, pero resulta profundamente descorazonador observar cómo con ciertos derechos se hacen excepciones y algunos de ellos van cayéndose de la nómina establecida y sancionada: el derecho a inmigrar ( $y$ no sólo a emigrar), la libre elección de la residencia, el derecho a la naturalización, el derecho de elegir nacionalidad, etc. Todos éstos son derechos con los que cada vez se regatea más, restringiéndose de manera discreta y paulatina. Sin duda, esta tendencia regresiva no ayuda ni a integrar a los inmigrantes ni a dar cabida política e institucional a la diversidad cultural que con ellos aflora, tal como se examinará en el apartado tercero.

\section{Algunos rasgos de la concepción republicana de la política}

La rehabilitación y recomposición del ideal republicano llevada a cabo en los últimos años «es, después de los trabajos de John Rawls, uno de los acontecimientos teóricos más importantes ocurridos en el dominio de la filosofía política», cuya relevancia estribaría en su cualidad para presentarse como «eje privilegiado de una problematización fecunda de los principios de la modernidad liberal» (Savidan, 2003, pp. 150-151). Desde la publicación de los trabajos de Wood, Skinner o Pocock, la modernidad política ya no puede seguir concibiéndose como hechura exclusiva del liberalismo. Aportaron datos y razones suficientes para pensar que algunos de los mecanismos que hoy tildamos de liberales son, en realidad, de genuina prosapia republicana; esta hipótesis se tor- na aún más plausible si aceptamos el siguiente punto de partida: el republicanismo representa «una vía de pensamiento que no sólo precede al liberalismo moderno, sino que también fue exitosamente solapada por su triunfo» (Skinner, 1996, p. 142). O, dicho de otro modo: la tradición republicana «ha sufrido durante mucho tiempo el hecho de que ha sido recubierta por la reescritura liberal» (Sadivan, 2003, p. 136). Por lo demás, resulta difícil negar una progresiva convergencia entre ambas tradiciones. Los principales representantes contemporáneos del republicanismo (especialmente, Pettit y Sunstein) pueden ser tildados, sin ejercer violencia alguna, de republicanos liberales ${ }^{5}$. Sin cuestionar radicalmente la democracia liberal, modelo político predominante en los países desarrollados, el republicanismo de corte liberal propone adaptar la democracia representativa a un modelo de ciudadanía mucho más participativa, aunque sin alcanzar los niveles de la democracia directa. Tanto republicanos como liberales reivindican igualmente el ideal de un «gobierno de las leyes» (y no de los hombres), concebido como forma más adecuada de evitar la arbitrariedad y garantizar la libertad como no dependencia de la voluntad de nadie. En consecuencia, para algunos no se trataría de proponer el republicanismo como una forma alternativa al liberalismo, sino de postular un liberalismo corregido (cfr. Ferrara, 2004, p. 6).

Las diferencias entre liberalismo y republicanismo no son empero nimias y se ponen en evidencia en sus divergentes concepciones de la ciudadanía. En la tradición liberal se adopta un lenguaje juridicista y la ciudadanía se asocia a la posesión de derechos individuales. En la tradición republicana se adopta más bien un lenguaje político y la ciudadanía se vincula con la participación en la esfera pública. En este sentido, resulta significativo que los derechos de sufragio - tanto activo como pasivo - hayan sido conside- 
rados tradicionalmente como el núcleo de la ciudadanía republicana: ciudadanos en sentido propio son aquellos que participan en el gobierno colectivo, bien sea de manera directa, bien sea votando a sus representantes. Mientras que el sociólogo británico Marshall describía la ciudadanía como el bucle que entrelazaba los derechos civiles, políticos y sociales, filósofos políticos desde la época de Aristóteles, pasando por Rousseau, hasta nuestros días, como Habermas o Walzer, han entendido la ciudadanía esencialmente como un status de plena pertenencia a una politeia libre y autogobernada ${ }^{6}$. Sin embargo, dentro de la tradición republicana se dan cita corrientes diversas que se relacionan con el pensamiento democrático de maneras incluso contrapuestas, que van desde un elitismo político hasta un radicalismo democrático. Así, muchos republicanos comprometidos con la independencia norteamericana no ocultaban su recelo frente a las asambleas populares y preconizaban medidas institucionales contramayoritarias. Republicano, y de tan pura cepa o más, era también el pensamiento de un Rousseau que concebía la libertad republicana como autonomía pública, esto es, como autogobierno activo ejercido participativamente por todos los ciudadanos. El autogobierno - la autonomía política de los ciudadanos- como noción clave de la noción republicana de libertad se completa, no siempre armoniosamente, con la idea del «gobiemo de las leyes» frente al poder arbitrario de los hombres, pues se entiende que sin ley no hay libertad. Pero no se trata tampoco de cualquier ley, sino tan sólo de aquella para cuya elaboración se ha contado con la participación de todos los afectados. Estos dos principios no son incompatibles, pero mantienen una relación de tensión, y dependiendo del extremo del que se estire más se explicarían esas variantes republicanas apenas esbozadas.
Como el liberalismo, también el republicanismo hace de la libertad y la autonomía el núcleo normativo de su propuesta, pero mientras que para el liberalismo la libertad es sinónimo de ausencia de coerción o de no interferencia, desde el republicanismo la concibe como ausencia de dependencia (Skinner) o de dominación (Pettit): una persona no es libre si depende de la voluntad de otros o si otros restringen sus posibles cursos de acción. Pero más allá de esta cuestión conceptual, desde el republicanismo se entiende la libertad de manera no meramente individual: sea lo que signifique la libertad, no cabe concebir ser libre sin una sociedad libre. Es por ello por lo que vinculan la libertad con el autogobierno, esto es, con la capacidad de la comunidad política para tomar control de sus propios destinos.

La distancia entre la tradición republicana y la liberal se pone igualmente de manifiesto en el divergente tratamiento dado a la noción de virtud cívica. La vida social, la convivencia política, precisa que sus miembros - miembros activos- presenten una fuerte disposición a poner la propia existencia al servicio de la cosa pública. Esta convicción republicana puede enfocarse conforme a los diversos autores de dos maneras básicas: al modo utilitarista (la virtud cívica es una condición imprescindible del buen funcionamiento de la democracia) o bien al modo perfeccionista o aristotélico (la virtud cívica eleva el carácter de los individuos e incluso representa la plenitud de la vida humana). Mientras que el liberalismo o bien asume la virtud cívica de modo utilitarista o bien ignora su papel, entre los actuales republicanos es común conjurar los peligros del perfeccionismo y buscan activar ciertas energías básicas para el debate democrático. Esto vuelve a ser bastante claro en el caso de Pettit y Sunstein, pues ambos rechazan que el republicanismo esté vinculado con concepciones concretas del bien. En todo caso, la tradición republica- 
na aboga por una concepción de la ciudadanía que coloca el acento en el valor de la participación política y en la noción del bien común; subraya también el hecho de que el ejercicio de la ciudadanía permite generar y mantener vínculos capaces de unir a una comunidad política. Sus impulsores teóricos tienden a ser mucho más conscientes que los liberales de que el individuo ha de disponer de vínculos afectivos, identitarios, emotivos, porque entienden que la mera razón no es suficiente móvil para la acción política, en general, $\mathrm{y}$, menos aún, para el ejercicio de la solidaridad social, en particular ${ }^{7}$. Consideran que las condiciones concretas de acción de los actores políticos forman parte de la teoría democrática (cfr. Hartmann, 2003). Todo ello contribuye a poner el énfasis en la relevancia de configurar «buenos ciudadanos», cumplidores de sus deberes públicos. Aunque la idea liberal avanzada por Kant (en La paz perpetua) de que el problema del buen gobierno «puede ser resuelto incluso en el caso de un pueblo de demonios [con tal de que tengan entendimiento]» tiene hoy en día multitud de partidarios, no cabe duda de que la vida en sociedad se ve facilitada con el ejercicio de las virtudes públicas. El componente subjetivo de la acción política debe completarse en todo caso con un adecuado diseño institucional. Es por eso que para los republicanos también resulte crucial, por ejemplo, tratar de evitar que unos pocos acumulen una indebida y desproporcionada influencia política.

Con frecuencia se le imputa al republicanismo y a la concepción de la ciudadanía impulsada por él un carácter particularista y excluyente, así como una actitud de desinterés con lo que acontece extramuros de la propia comunidad (cfr. Peña, 2003, p. 18). El republicanismo presentaría así una faceta igualitaria y comprometida hacia dentro, mientras que hacia fuera mostraría su cara insolidaria y excluyente ${ }^{8}$. Aunque históricamente hay numerosos datos que avalan dicha apreciación (tanto en la república romana como en las ciudades renacentistas del norte de Italia), el republicanismo contemporáneo opta por recuperar otros aspectos de esta tradición. Así, y lejos de sustentarse sobre raíces étnico-culturales irrepetibles, o postular una comunidad de sangre y suelo (Blut und Boden), pone el énfasis en el componente democrático de su pensamiento. Éste sería el caso de Cass S. Sunstein o de Jürgen Habermas. En particular, el filósofo alemán ha mostrado no sólo su sintonía con el republicanismo kantiano, sino que defiende explícitamente una «lectura del republicanismo realizada desde la teoría de la comunicación» (Habermas, 1999, p. 118). Partiendo de esa perspectiva retoma de la tradición republicana el énfasis en lo público, la valoración de la participación y la relevancia de la deliberación. En virtud de todo ello, bien cabría tildar el modelo político habermasiano de republicanismo deliberativo.

El caso de Habermas no constituye un fenómeno aislado en el pensamiento republicano, pues, como sostiene Ferrara (2004, p. 11), «el republicanismo tiene una clara afinidad electiva con las concepciones deliberativas de la democracia». Esta tradición política concede un valor intrínseco a la vida pública y a la participación política: el ciudadano ha de implicarse activamente en algún nivel en el debate político y en la toma de decisiones, ya que ocuparse de la política es ocuparse de la res publica, esto es, de lo que atañe a todos. De clara raigambre republicana sería la obligación de discutir y deliberar las normas jurídicas y las decisiones políticas entre todos los posibles afectados por las mismas: «Quod omnes tangit ab omnibus tractari et approbari debet», tal como rezaba una secular máxima del Derecho romano medieval (cfr. Luhmann, 1993). En todo caso, y frente a la lectura comunitarista que concibe a la sociedad republicana como una sociedad cerrada, estrecha en sus horizontes, princi- 
pios como el que se acaba de formular no sólo posibilitan, sino que alientan una praxis política mucho más abierta e inclusiva. $\mathrm{Al}$ acentuar la condición de posible afectado por una decisión política o una resolución jurídica se dejan oportunamente al margen los rasgos culturales característicos de cada individuo, ya sean étnicos, religiosos, de género o de herencia, de modo que éstos dejan de ser relevantes como criterios de inclusión/exclusión. Por otro lado, el propio ideal de deliberación parte de la constatación de que no hay razones absolutas a las que recurrir en caso de disenso. $\mathrm{Su}$ práctica requiere también de ciertos supuestos que incitan la intercomunicación entre los individuos, como, por ejemplo, la conciencia de que uno no posee toda la razón y, sobre todo, de que el otro también puede tenerla. Por eso, la concepción de la política deliberativa - el ideal de la discusión abierta y pública - implica que los ciudadanos deben asumir el pluralismo y la diversidad presentes en la sociedad y, en consecuencia, enfrentarse a ideas diferentes a las propias. De este modo, tienen la posibilidad de enmendar y depurar sus propias opiniones, así como alterar el orden de sus preferencias. Todas estas actitudes y capacidades subjetivas, estimuladas en un marco público, resultan sumamente recomendables, cuando no imprescindibles, para la convivencia pacífica en una sociedad compleja y plural ${ }^{9}$.

\section{La ciudadanía republicana en el contexto pluricultural generado por las migraciones}

Una gran parte de los conflictos políticos del mundo contemporáneo giran, tal como se ha señalado al inicio de este artículo, en torno a la organización y gestión política de la diversidad de sentimientos de pertenencia y a la convivencia entre diferentes formas de vida y de concebir el mundo. Incluso el indeclinable debate social -en torno a la persistencia de injustificadas desigualdades económicas entre los individuos - se ha visto absorbido y desplazado injustificadamente por las tensiones identitarias y culturales. En este contexto, la reciente revitalización del pensamiento republicano podría resultar inane si se mostrara incapaz de dar respuesta al reto que representa el fenómeno de la multiculturalidad y la multietnicidad en el seno de nuestras ciudades y países. Dar respuesta implica afrontar políticamente tanto las transformaciones sociales y culturales generadas principalmente por la inmigración como la articulación de la convivencia entre comunidades con formas múltiples de identidad.

Las intensas corrientes migratorias están en el origen de transformaciones de enorme calado tanto en lo demográfico, como en lo político, lo social y lo cultural. Sus efectos se tornan especialmente visibles en los ricos países occidentales, en donde se asiste a un acelerado proceso de constitución de sociedades de corte multicultural impulsado por la llegada de inmigrantes de las más variadas procedencias. Las migraciones constituyen sin duda el principal factor de multiculturalidad y sin ellas nunca hubiera surgido un espacio social realmente pluricultural. La respuesta política ante la diversidad política ha de empezar con la elaboración de una política migratoria articulada. Una política migratoria digna de dicho nombre debe incluir un conjunto de normas y medidas que permitan abordar coherentemente una serie de cuestiones diversas que, no obstante, están íntimamente conectadas entre sí: la regulación del acceso, la circulación, la estancia, condiciones laborales, así como la previsión de las diferentes irregularidades en la residencia y el trabajo, entre otros muchos asuntos. En este listado nada exhaustivo falta un instrumento central de toda política migratoria, a saber: la regulación de la adquisición de la ciudadanía. Este punto es crucial pues marca el horizonte de expectativas que se le ofrece al 
inmigrante dentro de una política de integración. Afrontar el reto de la emigración $\mathrm{y}$, a la postre, el de la diversidad cultural resultante implica enfocar la pertenencia y la lealtad política - vinculadas ambas con la noción de ciudadanía - de un modo diferente al habitual en los Estados nacionales.

La ciudadanía no es un principio universalista, sino un principio constitutivo propio de cada comunidad política. Determina quién constituye la comunidad política en cuestión, quién pertenece a la misma y quién no. Y en la misma medida en que es un principio constitutivo resulta ser también «un principio de inclusión que genera exclusiones colaterales» (Colom, 2002 , p. 36). Siendo esto así, lo cierto es que no todas las concepciones de la ciudadanía poseen los mismos efectos prácticos en este particular. Difieren entre sí en virtud del mayor o menor peso otorgado a los atributos identitarios, a los rasgos adscriptivos requeridos para su concesión. Cuanto mayor y más exigente sea el componente identitario de la ciudadanía menor será su capacidad de inclusión. Rasgos densamente definidos son instrumentos potenciales de discriminación y dificultan por ende la integración social. Dentro de este eje inclusión-exclusión, ¿en dónde se situaría la noción de ciudadanía preconizada por el nuevo republicanismo? Aunque la ciudadanía republicana resulta exigente en su componente político (se articula en torno a valores civiles y a una lealtad al orden jurídico-institucional), está exenta en principio de atributos étnicos y culturales, de tal modo que posee un poderoso potencial inclusivo.

Ante el pluralismo cultural e identitario cada vez más patente en las sociedades contemporáneas, y sin negar las indudables dificultades que siempre se presentan en la práctica política diaria, la ciudadanía republicana tiene en principio la enorme virtud de convocar al entendimiento entre pueblos e identidades, entre lenguas y cul- turas. En particular, el tipo de identidad colectiva característico de la tradición republicana, dado que no reposa sobre componentes étnico-culturales privativos como pudieran ser los lazos de sangre, lengua o religión, estaría bien posicionado a la hora de proporcionar las bases que aseguren el mínimo de lealtad política necesaria para mantener la integración de las sociedades plurales. Asegurar la lealtad y la cohesión en tales circunstancias representa un reto sobrevenido difícil de eludir:

«La considerable diversidad cultural de la sociedad moderna plantea problemas nunca antes enfrentados por la filosofía política tradicional. Algunos autores anteriores supusieron comunidades culturales homogéneas, donde los principios generales que desarrollaban podían ser aplicados a todos sus ciudadanos. [...] Por ejemplo, suponían que cualquier tipo de obligación política que propusieran [...] podía aplicarse de la misma manera a todos los ciudadanos y como más o menos autoridad moral. Hoy ya no podemos sostener la misma suposición» (Parekh, 1996, pp. 20-21).

Las fuentes normativas y emotivas de la obediencia y la lealtad política se ven con frecuencia alteradas por la proliferación de la diversidad. Si la lealtad política es una variable derivada en gran parte de las formas de pertenencia al orden sociopolítico, la emergencia y progresiva acentuación de formas plurales de pertenencia - compartidas e incluso divididas dentro de una misma comunidad política- debilita sin duda dicha lealtad. La respuesta más adecuada al advenimiento de este posible déficit no puede consistir, sin embargo, en potenciar una forma determinada de identidad colectiva cargada de elementos etnoculturales, aunque sean los propios del tronco mayoritario de la sociedad. El republicanismo tiene de partida la ventaja de que posibilita un marco de acción e identificación no exclusivo ni cerrado. Eso no significa, sin embargo, que represente una solución definitiva al problema ${ }^{10}$. 
Que se señale que el republicanismo representa un marco de referencia aceptable, no deja ser un planteamiento controvertido. Hasta hace poco se le consideraba como una respetable tradición política, digna de estudio, pero anquilosada y obsoleta. De ahí que más de un lector pueda revolverse incómodo al ver que se apela al republicanismo para dotar a la vida política de un mínimo armazón intelectual y de un cierto cimiento normativo, así como para solventar algunos de los escollos con los que se tropieza en las complejas y pluralistas sociedades modernas a la hora de encontrar un marco identitario aceptable para todos sus miembros. ¿Qué elementos de la tradición republicana podrían valer para dar respuesta a este difícil reto? $\mathrm{El}$ énfasis en lo público, el aprecio de la participación, la valoración de la deliberación $y$, particularmente, su noción de la ciudadanía constituyen un poderoso capital político aportado por dicha tradición que cabría recuperar para dicho fin.

$\mathrm{El}$ individuo es visto por el republicanismo, como ya se ha señalado, fundamentalmente desde el prisma de la ciudadanía: «alguien que se defina por su vinculación a la ciudad y entiende que la garantía de su libertad estriba en el compromiso con las instituciones políticas y el cumplimiento de sus deberes para con la comunidad» (Peña, 2004, p. 123). La ciudadanía es el ámbito por excelencia de la autorrealización del individuo: la participación política y la vita activa en la res publica. La tradición republicana promueve una noción robusta de ciudadanía y propugna una adhesión a la ley y al conjunto de instituciones públicas que hacen posible el ejercicio de la libertad civil. No en vano, una destacada convicción republicana es que «el no ejercicio de las libertades positivas lleva a una fragilización de las libertades negativas» (Sadivan, 2003, p. 157). Mediante la generalización del status de ciudadano se busca configurar en definitiva una identidad colectiva basa- da en la participación activa y responsable de los individuos en los asuntos públicos.

El enfoque republicano pretende configurar la esfera pública poniendo el énfasis especialmente en aquello que puede ser compartido por todos, en aquello que resulta común, dejando de lado las diferencias que separan para concentrarse en las similitudes y coincidencias que unen a los integrantes de cada sociedad. En esos elementos es en donde se halla el fundamento común de la legitimidad de la politeia, los principios de la justicia política. En consecuencia, el republicanismo respondería a los problemas políticos generados por el pluralismo cultural no atendiendo a una concepción culturalista (que deriva la individualidad de la pertenencia a una cultura particular), sino primando la solución política. El punto crucial consiste al final en que «la identificación del ciudadano con la empresa común sea obtenida por medios políticos» (Del Águila, 2004, p. 55). Ya el republicanismo clásico, de Cicerón a Maquiavelo, buscaba y priorizaba la identificación de los ciudadanos con las leyes que hacían posible la libertad. Más modernamente, Habermas, por ejemplo, postula la identificación de los ciudadanos con el valor intrínseco del pluralismo de formas de vida en el marco de la república común que las hace posibles. Frente a nociones etnicistas y sustancialistas de la identidad política, esta variante republicana - que bebe de las fuentes de Rousseau y Kant - posee virtudes incluyentes: «La autodeterminación democrática no tiene el sentido colectivista y al tiempo excluyente de la afirmación de la independencia nacional y la realización de la identidad nacional. Más bien tiene el sentido inclusivo de una autolegislación que incorpora por igual a todos los ciudadanos» (Habermas, 1999, p. 118).

Si eso es así, entonces desde el republicanismo se podría ensayar una respuesta política adecuada al reto de integrar la diversidad cultural: «Desde luego, el 
patriotismo republicano tiene una dimensión cultural, pero es primariamente una pasión política basada en la experiencia de la ciudadanía, no en elementos prepolíticos comunes derivados del haber nacido en el mismo territorio, pertenecer a la misma raza, hablar la misma lengua, adorar a los mismos dioses o tener las mismas costumbres» (Viroli, 2001, p. 7). Así, de acuerdo con una concepción republicana de la ciudadanía, su titularidad no se vincularía a una determinada relación de pertenencia, sea ésta un linaje o una etnia, ni al dominio de una lengua, ni a un lugar de nacimiento, sino que se asocia fundamentalmente a la condición de residente en el territorio de una comunidad política $\mathrm{y}$, sobre todo, al hecho de compartir una vida en común (cfr. Peña, 2003, pp. 2526). En concordancia con ello, se rechazaría el denominado ius sanguinis como principio preferente de asignación de la ciudadanía $y$, por el contrario, habría que adoptar un ius soli, aunque cualificado: al requisito habitual de la residencia acreditada habría que añadirle la implicación activa en la vida de la sociedad (o al menos, la certificación de las condiciones y capacidades que habiliten para ello). La referencia no sería entonces la pertenencia a una nación (entendida en su sentido prepolítico de comunidad de historia, lengua y tradiciones culturales), sino, como ya se ha indicado, la integración en una politeia 0 , en términos modernos, el Estado:

«La nación representa el "medio" en que el hombre nace, una sociedad cerrada a la que se pertenece por derecho de nacimiento. El Estado [...] es una sociedad abierta, que rige sobre un territorio en que su poder protege la ley y la hace. Como institución legal, el Estado sólo conoce ciudadanos, no importa de qué nacionalidad; su orden legal está abierto a todo el que dé en vivir en su territorio» (Arendt, 2005, p. 257).

La tradición política del republicanismo siempre ha preconizado este tipo de identidad colectiva abierta basada en la participación y en la responsabilidad de todos los individuos. No es la pertenencia a una etnia o la adscripción a un credo religioso o ideológico lo que reúne o identifica al miembro de la comunidad política. El ideal de la autodeterminación de los ciudadanos es, sin duda, la intuición central del republicanismo, un ideal que cabe describir así: «El corazón del autogobierno democrático es el ideal de la autonomía pública, a saber, el principio de que quienes están sujetos a la ley también deberían ser sus autores» (Benhabib, 2005, p. 154).

La utilización de la ciudadanía como mecanismo de cohesión social constituye, sin embargo, una cuestión abierta a debate. La tesis de que conceder la ciudadanía equivale a integrar no siempre está convalidada por la práctica social, por más que sea recomendable normativamente. Es cierto que la implementación de políticas de inclusión cívica dirigidas a extender el estatuto de ciudadanía a los inmigrantes ya establecidos tiene una indudable ventaja en aras de su integración social y política: impide la consolidación de una categoría, perpetuada de padres a hijos, de residentes no ciudadanos, de metecos. No es, con todo, un instrumento milagroso, pues el mero hecho de conceder el status de ciudadanía a los inmigrantes tras un período razonable de asentamiento no equivale automáticamente a integrarlos (en ello tendría razón Sartori, 2001), pero, por el contrario, también es cierto que mantenerlos apartados de la participación política y excluidos de la función pública, por mencionar tan sólo dos aspectos onerosos que habitualmente la privación de la ciudadanía comporta, no ayuda nada en este sentido. No puede negarse, en todo caso, que atribuir un estatuto definido de derechos y obligaciones evita formas flagrantes de marginación (laboral, civil, tributaria, etc.). La concesión de la ciudadanía constituye una condición necesaria para la inte- 
gración social plena, aunque, desde luego, no es condición suficiente.

Si los derechos de sufragio son centrales en la concepción democrática de la ciudadanía, resulta relevante observar de qué modo se les reconoce y se les extiende tales derechos a dos colectivos bien diferenciados de individuos: los ciudadanos no residentes (o residentes en el extranjero) y los residentes no ciudadanos (extranjeros residentes). Las diversas formas de reaccionar ante estas situaciones retratan con bastante exactitud modelos de comunidad política bien diferenciados (cfr. Bauböck, 2005, pp. 765-766). Pero si importantes son los derechos de participación política, tanto o más son los derechos civiles, económicos y sociales, al menos en la apreciación de los inmigrantes. En los Estados democráticos liberales, los derechos civiles y sociales - apuntados por Marshall como soporte de las primeras fases de la evolución de la ciudadanía en la edad contemporánea- hace tiempo que se han desconectado del status formal de ciudadanía. El disfrute de las libertades civiles básicas se entiende cada vez más como un derecho humano universal. La educación pública, la asistencia sanitaria y las prestaciones de la seguridad social se consideran beneficios derivados bien de la condición de residente o bien del status de trabajador y contribuyente. El término denizenship - acuñado por Tomas Hammar (1990)describe ese nuevo y difuso status legal de los extranjeros residentes de larga duración por el que en la práctica disfrutan de la mayoría de los derechos de ciudadanía. Sin llegar a ser titulares de la condición de ciudadanía, tales individuos ocupan un lugar intermedio entre extranjeros y ciudadanos, una posición que en muchos aspectos resulta mucho más próxima a la de estos últimos. De este modo se invertiría el esquema secuencial de Marshall: la ciudadanía social de los inmigrantes antecede y se detiene en el umbral de la ciudadanía política. Es cierto que, contemplado desde la óptica exigente del republicanismo, que persigue la equiparación legal de todos los individuos, tal status no deja de constituir una zona gris de transición. Pero, por otro, desde una perspectiva más indulgente y quizás más realista, constituye una respuesta razonable para conceder algún tipo de acomodo a los nuevos vecinos procedentes de los flujos migratorios.

En este artículo se ha mantenido que la concepción republicana está en principio bien dotada para dar cabida a la diversidad cultural. Ello, sin embargo, no significa que una política republicana haya de plegarse acríticamente a todas las demandas realizadas en su nombre. La primacía del momento democrático es incuestionable también en este punto. Las reclamaciones y exigencias de las minorías culturales - tanto de las minorías etnonacionales asentadas en determinadas regiones del territorio estatal o de los grupos de inmigrantes dispersos por ese mismo territorio- no son el punto de llegada de la política democrática, sino un punto de partida. Las reivindicaciones en nombre de las peculiaridades culturales o de las identidades no están por encima del escrutinio democrático.

En una sociedad multicultural, una identificación estable y amplia de los individuos con el Estado sólo resulta factible a la larga si, en contra de lo que afirma el liberalismo clásico, además de garantizar los derechos y libertades individuales, las instituciones públicas se muestran comprometidas en la defensa de la pluralidad de culturas en las que los ciudadanos se inscriben. Desde una perspectiva republicana, lo que se pretende es «el establecimiento y la aplicación estricta de derechos universales de ciudadanía e igualdad de oportunidades, lo cual, después de todo, incluye la oportunidad de perseguir una gran variedad de valores, estilos e identidades» (Offe, 2004, 2006). Las cuestiones relativas a la conducción de la propia vida no constituyen en sí mismas objeto de regula- 
ción política, pero sí que lo son las condiciones formales y materiales que las posibilitan. Lejos de negar la diversidad cultural —de ignorar las diferentes identidades coexistentes- lo que se trata es de hacerlas posibles. En este sentido, no puede resultar indiferente cuál sea el modelo constitucional que haga suyo una política inspirada en valores republicanos. Si busca realmente dar cabida a la diversidad cultural, el republicanismo ha de amparar una comprensión de la constitución como un proyecto abierto, que propicie una convivencia dúctil, respetuosa de la pluralidad, esto es, como una propuesta de soluciones $\mathrm{y}$ coexistencias posibles ${ }^{11}$. En las sociedades pluralistas actuales, es decir, en las sociedades marcadas por la presencia de una diversidad de grupos sociales con culturas, identidades proyectos diferentes, pero sin que ninguno tenga fuerza suficiente para hacerse exclusivo o dominante, «a la constitución se le asigna no la tarea de establecer directamente un proyecto predeterminado de vida en común, sino la de realizar las condiciones de posibilidad de la misma» (Zagrebelsky, 1995, p. 13).

\section{BIBLIOGRAFIA}

ARENDT, Hannah (2005): «La nación», en Ensayos de comprensión 1930-1954, Madrid, Caparrós, pp. 255-260.

BAUBÖCK, Rainer (2005): «Expansive Citizenship - Voting beyond Territory and Membership», en Political Science \& Politics, vol. 38, núm. 4, pp. 763-767.

BaUman, Gerd (2001): El enigma multicultural, Barcelona, Paidós.

BÉJAR, Helena (1999): «El corazón de la república», en Claves de razón práctica, núm. 91, pp. 37-42.

BenhabiB, Seyla (2005): Los derechos de los otros, Barcelona, Gedisa.

COHEN, Jean L., y Arato, Andrew (2000): Sociedad civil y teoría política, México, FCE.
Colom, Francisco (2002): «La gestión de la diversidad etnocultural», en $\Delta \alpha u ́ \mu \omega \nu$, núm. 27, pp. 21-42.

DEL ÁGuILA, Rafael (2004): «El (multi)culturalismo frente al liberalismo y la democracia», en Francesc PAU Y VALL (coord.), Ciudadanía y politica, Madrid, Tecnos, pp. 43-55.

Ferrara, Alessandro (2004): «El desafío republicano», en Claves de razón práctica, núm. 139, pp. 4-12.

GUTMANN, Amy (2001): La educación democrática, Barcelona, Paidós.

HABERMAS, Jürgen (1998): Facticidad y validez, Madrid, Trotta.

-(1999): La inclusión del otro, Barcelona, Paidós.

Hammar, Tomas (1990): Democracy and the Nation State. Aliens, Denizens and Citizens in a World of International Migration, Avebury, Aldershot.

HARTMANN, Martin (2003): Die Kreativität der Gewohnheit. Grundzüge einer pragmastischen Demokratietheorie, Fráncfort, Campus.

LuHMANN, Niklas (1993): «Quod omnes tangit...», en Rechtshistorisches Journal, núm. 12, pp. 36-56.

MARShall, T. H., y BOTTOMORE, Tom (1998): Ciudadanía y clase social, Madrid, Alianza.

OFFE, Claus (2004): Las nuevas democracias, Barcelona, Hacer.

PAREKH, Bhikhu (1996): «Algunas reflexiones sobre la filosofía política occidental contemporánea», en La política, núm. 1, pp. 5-22.

PeÑA, Javier (2003): «Ciudadanía republicana y cosmopolitismo», en $\Delta \alpha i ́ \mu \omega \nu$, núm. 28 , pp. 17-33.

-(2004): « $i$ Tiene futuro el republicanismo?», en F. QueSADA (ed.), Siglo XXI: ¿un nuevo paradigma de la política?, Barcelona, Anthropos, pp. 119-147.

RAWLS, John (1996): El liberalismo político, Barcelona, Crítica.

RORTY, Richard (1998): «La justicia como lealtad ampliada», en Pragma- 
tismo y politica, Barcelona, Paidós, pp. 105-124.

SADIVAN, Patrick (2003): «La crítica republicana del liberalismo», en J. CoNILL y D. A. CROCKer (eds.): Republicanismo y educación cívica. ¿Más allá del liberalismo?, Granada, Comares, pp. 135-158.

SALMERón, Fernando (1996): «Ética y diversidad cultural», en Osvaldo GUARIGLIA (ed.), Cuestiones morales, Madrid, Trotta-CSIC, pp. 67-85.

SARTORI, Giovanni (2001): La sociedad multiétnica, Madrid, Taurus.

SKINNER, Quentin (1996): «Acerca de la justicia, el bien común y la prioridad de la libertad», en La Política, núm. 1, pp. 137-149.
SOYSAL, Yasemin N. (1994): Limits of Citizenship, Chicago, Univ. of Chicago Press.

SUNSTEIN, Cass S. (2003): República.com. Internet, democracia y libertad, Barcelona, Paidós.

ThIEBAut, Carlos (1998): Vindicación del ciudadano, Barcelona, Paidós.

WolIN, Sheldon S. (1996): «Democracia, diferencia y re-conocimiento», en $L a$ política, núm. 1, pp. 151-170.

Wood, Gordon S. (1969): The American Revolution, The Creation of the American Republic, Williamsburg, North Caroline U.P.

ZAGREBELSKY, Gustavo (1995): El derecho dúctil. Ley, derechos, justicia, Madrid, Trotta.

\begin{abstract}
1 La reflexión sobre la diversidad no es ninguna novedad en la filosofía política. Quizás ahora se le preste una mayor atención, se hayan incluido nuevas consideraciones y sean observables ciertos cambios en su conceptualización. De hecho, a lo largo de la historia de la filosofía política esta noción ha ido adquiriendo distintas acepciones (cfr. Wolin, 1996, pp. 155-156, 158). En la reflexión ilustrada sobre la tolerancia (véase, p. ej., Locke o Voltaire) la atención se dirigía hacia la diversidad de adscripciones más o menos voluntarias a las que el individuo no está adherido biológicamente: sería el caso del pluralismo de creencias (religiones, cosmovisiones e ideologías). Por el contrario, en la reflexión contemporánea sobre el multiculturalismo el punto de partida es, con frecuencia, el reconocimiento de la multiplicidad de adscripciones a rasgos adheridos involuntariamente a sus portadores: color de la piel, género, preferencia sexual, etc. No obstante, la pluralidad religiosa y, sobre todo, la lingüística (de la que difícilmente puede decirse que sea biológica, pero tampoco que sea voluntaria) también son objeto preferente de estudio. Las consecuencias políticas de esta distinción serían importantes: en el primer caso, las diversidades serían materia negociable; en el segundo, serían irreductibles y requerirían concesiones o claudicaciones. No es extraño, sin embargo, que por conveniencia un tipo de diferencia sea reconceptualizado como si formara parte de la otra categoría.
\end{abstract}

${ }^{2}$ El hecho de que constituya un término estrella en el debate político actual no implica, por supuesto, ni que su significado sea inequivoco ni que su aceptación sea generalizada. Así, tanto para la nueva derecha como para el neoliberalismo «la idea de ciudada nía es uno de tantos dislates progresistas que sólo sirven para calentar los cascos de la gente respecto al espacio social que ocupa, y para que los súbditos acaben por creer que no son sólo eso, súbditos obligados a dejarse gobernar, sino también personas dotadas de derechos» (Robert Moore, prefacio a T. H. Marshall 1998, 9).

${ }^{3}$ El texto de referencia no es otro que el de T. H. Marshall «Ciudadanía y clase social», publicado en 1950 (Marshall y Bottomore, 1998). He aquí su ya clásica definición: «La ciudadanía es aquel estatus que se concede a los miembros de pleno derecho de una comunidad. Todo el que lo posee disfruta de igualdad tanto en los derechos como en las obligaciones que impone la propia concesión» (Marshall, 1998, 37). La ciudadanía equivale, pues, al status legal que recopila los derechos que el individuo puede hace valer frente al Estado. En la concepción de Marshall, los derechos sociales serían aquellos que posibilitan que los sujetos más desfavorecidos se integren en la corriente principal de la sociedad y ejerzan plenamente sus derechos civiles y políticos. Esta idea contribuyó enormemente a la reconciliación del pensamiento socialdemócrata con la noción liberal de los derechos. 
4 No sólo desde presupuestos comunitaristas se cuestiona la aspiración de universalidad del primer Rawls. Así, p. ej., Rorty propone describir la noción de «justicia» como el nombre que recibe la «lealtad ampliada» más allá de nuestros grupos primarios de parentesco y pertenencia (Rorty, 1998). Se enfrentaría así a quienes desde posiciones kantianas conciben la justicia (o, si se prefiere, el «actuar justamente») como una «obligación moral universal».

5 Siguiendo al mayor paladín del liberalismo contemporáneo, John Rawls (1996, pp. 239-241), cabe distinguir dos versiones del republicanismo: el republicanismo clásico y el humanismo cívico. El primero se caracteriza por la reivindicación de la participación activa de los ciudadanos en la vida pública como medio para preservar sus derechos y libertades; el segundo, concibe la participación política como el componente crucial de la concepción de la vida buena $y$, a la postre, como una forma de vida con la que iría adosada una determinada doctrina comprehensiva. Rawls considera que mientras que no existe incompatibilidad alguna entre liberalismo y republicanismo clásico, liberalismo y humanismo cívico se contraponen abiertamente.

${ }^{6}$ La idea de que el núcleo de la ciudadanía viene dado, sobre todo, por los derechos de participación política se remonta al menos hasta Aristóteles: «El ciudadano no lo es por habitar en un lugar determinado [...], ni tampoco los que participan en ciertos derechos como para ser sometidos a proceso judicial o entablarlo [...]. Un ciudadano en sentido estricto se define por ningún otro rasgo mejor que por participar en las funciones judiciales y en el gobierno» (Aristóteles, Política, Lib. III, 1275a).

${ }^{7}$ El pensamiento republicano puede representar en este sentido una «tercera vía» entre el liberalismo y el comunitarismo, «en la medida en que parece ser capaz de conjugar la vinculación comunitaria que reclaman unos y los derechos civiles de los ciudadanos que reclaman los otros» (Peña, 2004, p. 121).

8 Con cierto fundamento histórico suele presentarse la propuesta republicana como una perspectiva normativa particularista y excluyente, como un planteamiento político que implica un espacio público clausurado y homogéneo, notas que así presentadas suponen el establecimiento de condiciones poco favorables para dar cabida a la diversidad cultural. Desde estos planteamientos sería igualmente difícil asumir el universalismo moral contemporáneo expresado en los derechos humanos. En la variopinta y poco coherente tradición republicana hay autores ciertamente que responden a este negativo cliché. Entre ellos se encontrarían algunos pronunciamientos de Rousseau, que ado- lecen de un espíritu exclusivista, cuando no xenófobo. Esta negativa caracterización del patriotismo republicano sigue siendo moneda corriente. Así, por ejemplo, Béjar (1999, p. 39) sostiene que constituye «una pasión excluyente y absorbente. Deja fuera a los extranjeros porque no contribuyen a crear leyes ni a mantener las costumbres de la libertad: aquellos que se quedan al margen del proyecto comunitario devienen extraños, cuando no enemigos. La identificación entre pertenencia y autonomía produce un cierre particularista incuestionable que el actual aggiornamento del republicanismo pretende disimular».

9 El ideal de la deliberación no es el único tópico de la tradición republicana recuperable en tiempos de marcada complejidad y diversidad cultural. También serían rescatable por ejemplo, la defensa del Estado laico o la promoción de la escuela pública. La vindicación de una visión laica de la esfera pública forma parte de los motivos básicos de la tradición republicana y este ingrediente laico posee enormes virtualidades para la integración igualitaria de las diversas formas de vida y visiones del mundo dentro de la vida pública. Ninguna de estas diferentes perspectivas puede demandar primacía y ninguna puede ser discriminada si no atenta contra los principios que permiten el pluralismo. Este planteamiento también ha de plasmarse en el sistema educativo (cfr. Gutmann, 2001). Dado que la escuela es el espacio privilegiado para la cohesión social y la formación democrática de la ciudadanía, cualquier forma de discriminación debe pararse a la puerta de la escuela. En este sentido, actitudes como el proselitismo, la provocación y la propaganda religiosa en el ámbito escolar chocan no sólo con el laicismo, sino con la concepción republicana de lo público.

30 Desde la filosofía política, en estas cuestiones se ha de ser muy consciente de las propias limitaciones: el problema práctico de la obediencia y la lealtad polí tica en un Estado culturalmente plural carece de solución filosófica. A lo sumo, cabe apuntar marcos normativos para su posible articulacion, argumentos e ideas regulativas sobre las posibles referencias para la lealtad política, pero la integridad de las estructuras sociales y estatales obedece a una compleja constelación de factores que no está en manos de nadie manipular arbitrariamente, como si se tratara de una obra de ingeniería política

11 Habermas — siguiendo aquí a Peter Häberletambién entiende la constitución de manera dinámica esto es, como un proyecto siempre inconcluso y carente, en consecuencia, de cualquier sesgo esencialista (cfr. Habermas, 1998, pp. 465-466). 